\title{
Smart City in Terms of Social Innovations and Human Capital
}

\author{
Richard Jurenka ${ }^{1}$, Dagmar Cagáňová ${ }^{1}$, Natália Horňáková ${ }^{2}$, Augustín Stareček $^{2}$ \\ Slovak University of Technology in Bratislava ${ }^{1,2}$, Faculty of Materials Science and \\ Technology in Trnava ${ }^{1}$, Institute of Industrial Engineering and Management ${ }^{2}$, Trnava, \\ Slovakia ${ }^{1,2}$ \\ \{richard.jurenka, dagmar.caganova, natalia.hornakova, \\ augustin.starecek\} estuba.sk
}

\begin{abstract}
Increased dynamics of social processes imposes requirements on innovative approaches and solutions for resolving social problems in contemporary world that exceed the established ways of thinking and acting. A social innovation as a term covers a wide range of activities and tools. The widest definition specifies social innovation as any new strategies, concepts and ideas. The first goal of the submitted article is to identify and define the key features and tools of social innovations. The second goal is to examine usage of social innovations tools and the last aim is to improve working conditions of man, satisfy basic human needs, and ensure continuous and quality education through the proposed social innovations. The most important contribution of the article is to highlight the necessity of human capital in industrial enterprises. Research methods, consist of analysis, synthesis, deduction, induction and comparison, are used in the article.
\end{abstract}

Keywords: smart city, innovation, social innovation, change, human capital

\section{Introduction}

Smart city is a community that is efficient, liveable, sustainable, and which increase a quality of life. Smart city cannot exist and develop without smart human capital. Smart human capital is the fundamental element of each smart city. Only smart people could be author of smarts solutions and create smart ideas which transforms common city to smart city. Improvement of living conditions, working conditions and continual improvement quality of human capital can be achieved by social innovation. Social innovations in the context of a smart city allow achieving sustainable development, which in these days could ensure a higher quality of life. The main goal of social innovations is to support human capital. Involvement of government and insertion of these social goals in policy making process and defining common strategy for each city could be helpful.

Vision of Industry 4.0 will have a significant impact on employee qualification and on the labour market in general, whereby it will be also necessary to consider all social aspects and consequences. Impact of Industry 4.0 will lead to new work principles, change of employee's role, changes in structure of job description of the most professions which will require new knowledge. Abovementioned impacts will 
affect the employee development and will also require the new settings of labour market and educational systems.

\section{What is a "smart city"?}

Smart city (Fig. 1) is a city equipped with basic infrastructure which gives a decent and respectable quality of life, a clean and sustainable environment through application of specific smart solutions [1].

The most effective definition of a smart city is a community that is efficient, liveable, and sustainable - and these three elements go hand-in-hand. A sustainable community is one which reduces the environmental consequences of urban life and is often an output of efforts to make the city more efficient and liveable [2].

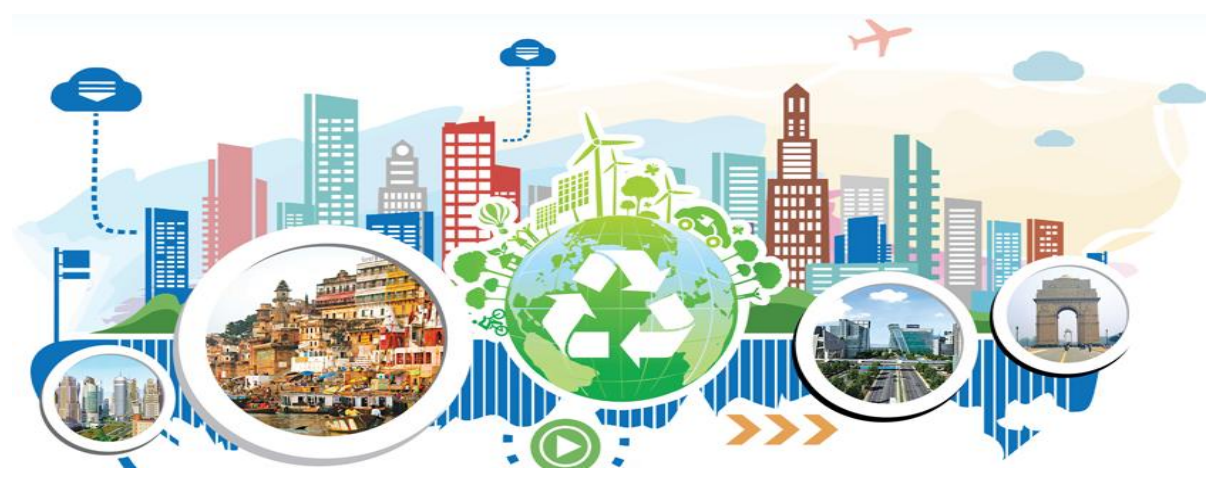

Fig 1: Smart city [3].

The British Standards Institute (BSI) defines the term smart city as "the effective integration of human, physical and digital systems with the aim to built environment which can deliver sustainable and prosperous future for its citizens".

Citizen-focused definitions consider smart city as friendly, clean and with well developed transport infrastructure. In citizen-focused definitions are also familiar words like "technology", "connected", "internet" and "modern" which are extend the right meaning of smart city [4].

\subsection{Basic and smart infrastructure}

Basic infrastructure (Fig. 2) includes assured water and electricity supply, efficient urban mobility and public transport, sanitation and solid waste management, egovernance and citizen participation, robust information technology connectivity, safety and security of citizens [1].

Reaching of smart infrastructure is possible only in the way of applying information and communications technology (ICT) infrastructure. The availability and quality of the ICT infrastructure are important for smart cities. Indeed, smart object networks play a crucial role in building smart cities a reality. ICT infrastructure includes wireless infrastructure (fibre optic channels, Wi-Fi networks, wireless hotspots, kiosks), service-oriented information systems. The implementation of an 
ICT infrastructure is fundamental to a smart city's development and depends on factors related to its availability and performance. There is a lack of literature that focuses on ICT infrastructure barriers of smart cities initiatives [5].

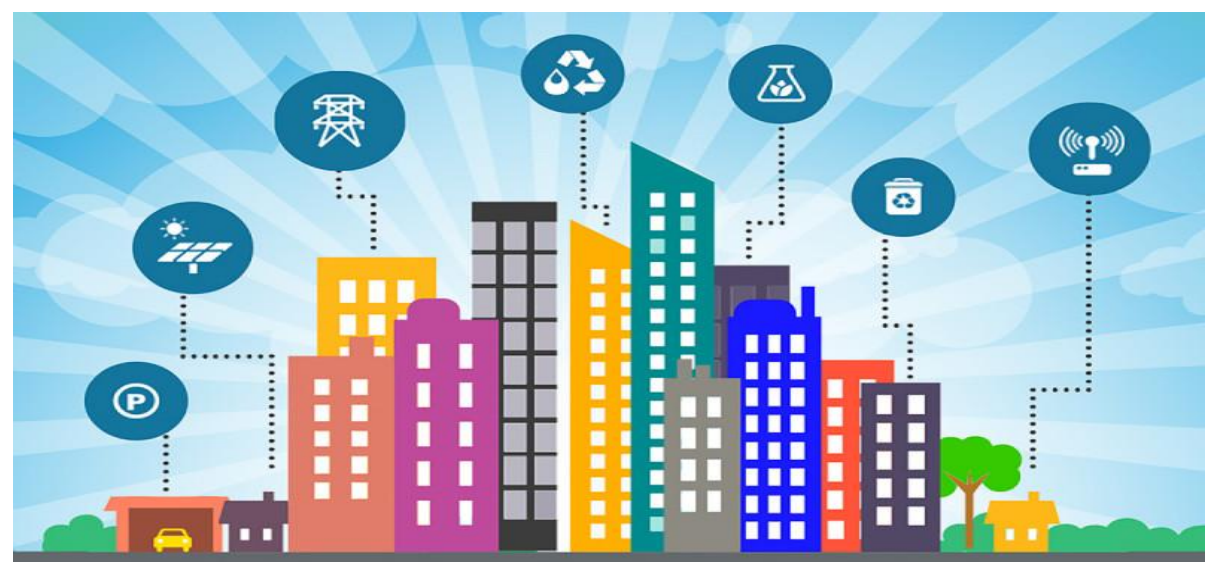

Fig. 2: Smart infrastructure [6].

\subsection{Smart solutions}

Smart solutions consist of following aspects: relevant public information, transformation waste to energy and fuel, transformation waste to compost, renewable source of energy, efficient energy and green building, smart pedestrian crossing, electronic service delivery, citizens' engagement, $100 \%$ treatment of waste water, smart meters and management, monitoring water quality, smart parking, intelligent traffic management system and others [1].

Now more than ever, cities need to provide public services more efficiently along with supporting sustainable and long term economic growth. The latest researches suggest that the best way to do this is becoming "smart". This generally means to use new technologies (mainly information and communication technologies) and data to improve service delivery and address various economic, social and environmental challenges. For example: smart energy meters can help cities manage energy demand, reduce cost and safeguard the environment while the move towards online health consultations can also reduce cost and improve the quality of services. Smart transport and mobility initiatives like traffic control centre can also help the city manage traffic flows and reduce traffic jam, while making real time bus arrival data publically available can allow development of new mobile applications that make commuting in the city easier [5].

\subsection{Connectivity in smart city}

Infograph (Fig. 3) outlines the key components of a smart city, especially components of top medium-sized smart cities [7]. 


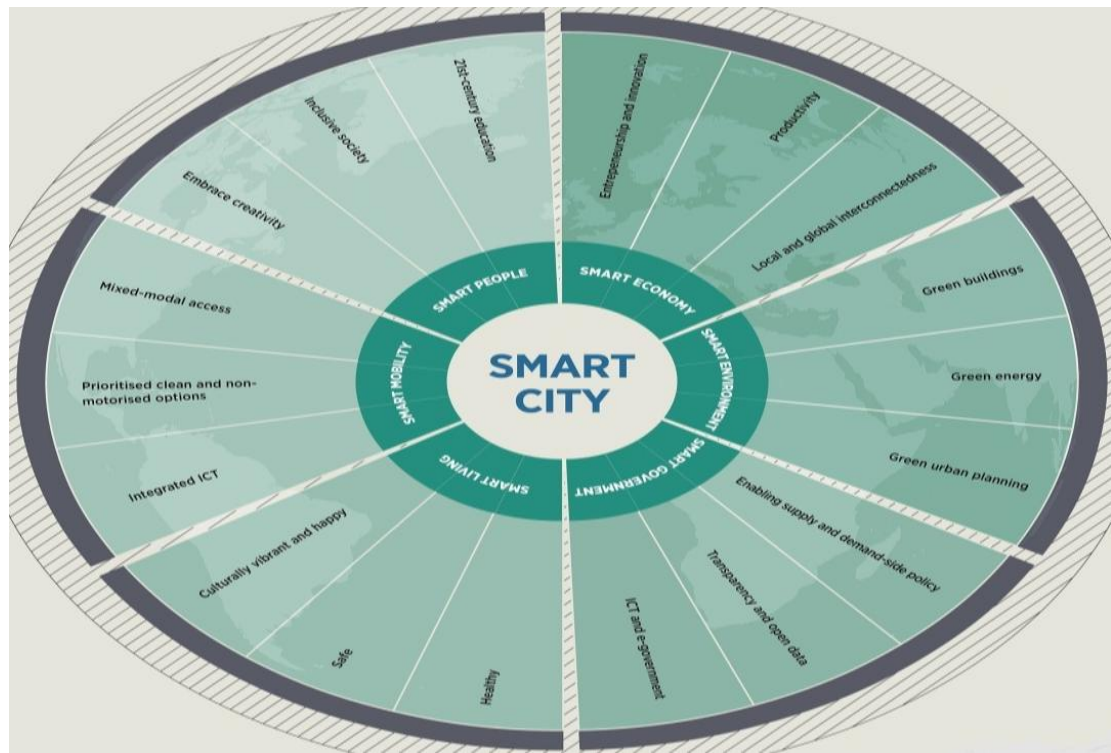

Fig. 3: Connectivity in smart cities [7].

Smart city consists of six key elements: smart people, smart mobility, smart economy, smart environment, smart government and mobility. Abovementioned six elements are essential for achieving the smart city goals in real meaning.

\section{Human capital and social innovations}

Smart city is not only about technological approach, information revolution, smart mobility or energy efficiency. Smart city is particularly about smart people, because without smart people nothing new and progressive will not arise. Equally important aspect of smart city is its human capital and social innovation, which concern attention on the well-being of people.

Future changes will become an opportunity for growth of qualification, flexibility, for innovative ideas and social innovations. Technical knowledge will be modified by Industry 4.0 and pure technical knowledge will retreat to skills which are capable draft appropriate solutions for certain applications in praxis. In future will be crucial how and in what extend managers and technicians will be able to identify and utilise new opportunities of digital solutions. All of this requires completely new competencies.

Investment into the human capital through skills development and training is clearly vital for maintaining of production base in Europe. Availability of skilled labor is a key factor for growth and competitiveness of the automotive industry and will be essential to achieve leadership in breakthrough technologies. On the other hand, the industry already faces the lack of skilled labor and experience to clearly identify the skills that will be necessary in the future. According the previous it is 
necessary to ensure appropriate qualifications of the staff and their training and lifelong learning. Lifelong learning could be achieve by social innovations.

Lack of skills is a major concern. It is necessary to take urgent measures with long-term national targets to substantially modernize education and training in order to update the skills range through the new school curricula, provide education and training by using ICT and new forms of partnerships with employers. At European level, this problem is not only related to the automotive industry but also to other industries. The European Commission early in the statement on revaluation of investment in education and skills in order to achieve better socio-economic outcomes sets the strategic priorities to address these issues. As a cross-cutting issue, this topic is addressed within the framework of the European employment policy. In addition, following sector initiatives will be crucial. Due to changes in the necessary skills that can be observed on the EU labor market, the attraction of the new labor from the countries outside the EU is possible supplementary solution of this problem.

\subsection{Social innovations}

Social innovation as a concept and a summary of the tools includes a wide range of activities. The widest possible definition specifies social innovation as all new strategies, concepts, ideas and organizations that enhance and support the improvement of conditions for the functioning of civil society.

Generally social innovations includes all activities that results into the qualitative changes of basic social structures, respectively innovations that have targeted significant social impact.

Authors from the University of Oxford perceived social innovation especially as new ideas and their practical applications that address dissatisfied social needs of people. Innovations are generators of processes of the desired social change [9].

Social innovation for the purpose of submitted article is understood as ideas to help individual actors to organize their activities and social interactions in order to successfully achieve common objectives. Social innovations also may include the development of new processes and procedures for structuring common work, introduction of new social practices in the group and the creation of new kinds of social institutions [8].

Social innovations are sustainable only if they are:

- based on real social needs;

- addressed to specific community;

- initiated by leaders;

- realized as act for the common good;

- without personal interests;

- taking place in the context of existing systems and subsidize each other.

The notion of social innovation is not a new phenomenon, throughout the history people have always sought to find new solutions for pressing social needs [10]. It nevertheless social innovations always copied the innovation of technology processes in the past. Nowadays there is institutional support for social innovations, because in current time, there is also important to promote social innovation.

Key definition criteria for social innovations are following [8]: 
- focus on dissatisfied needs or social problems;

- novelty of the approach that brings positive social changes (changes in behavior, attitudes, social impacts);

- production of added social value (social synergistic effect on the quality of social relationship);

Social innovation is characterised by following specifications:

- social innovation can be stated as a new combination or hybrid integration of existing elements (it is not the discovery of new elements, but the innovation can be found in a new connection, innovative application of known elements in non-traditional contexts);

- their application in practice involves crossing the established borders;

- produces new social relationships and links (networking) previously isolated individuals and groups.

Social innovation can be simply defined as new ideas, based on innovative combination of previously separated elements that work in practice in order to achieve social objectives. This distinguishes innovation from improvement, which only brings partial incremental changes and also from creativity that is vital for innovation, but do not include the application, or implementation into practice, which is the criterion of applicability of a new idea. In this sense it is clear that the term innovation is not only a new idea, or the invention, but also it is practical application in practice [9].

Social innovation is associated with the development of activities and services that are motivated by social objectives. This distinguishes them from business innovation, which are generally oriented to maximize the profit, which may also have positive social effects, but they are not their definition criterion [7].

Agenda of social innovator is to improve the conditions of human existence and life. Social innovator is making efforts to achieve social development, which is related to following [8]:

- improving of opportunities for all employees of the company;

- satisfying basic human needs;

- achieving the decent working conditions;

- offering higher standards of health services;

- continuous and quality education.

Technical and technological innovation requires handling new techniques and technical resources. Social innovation often requires changes in values, attitudes and people's opinion, including learned ways of social action what increases the demand for their application. Current social innovations are also associated with the development of social partnership, state and civil society, which places specific requirements on the ability of stakeholders to build and develop social capital.

Social innovation in the form of a contribution to better and more effectively way of meeting the social needs and solve their problems often become the main objective of social innovation. Sometimes social innovations can even be more important than technological innovation for the successful growth and prosperity of enterprise.

Social innovation can bring social development, which consequently brings the improvement of opportunities and conditions for all employees. What is more social 
innovation can ensure better working conditions, meet human needs, effectively motivate and encourage the staff, provide continuous and quality education.

\section{Conclusion}

Smart city, despite its great potential deals with the human capital and social problems in the society and in industrial enterprises insufficiently. It is important that representatives or participants of smart city should pay more attention to promote this concept among the general public, along with stronger implementation into the sphere of social innovation in industrial enterprises at home and abroad.

The vision of smart cities gained importance in several years ago, smart city have perspective future in all its components. Smart city have a number of dimensions which are not only related to technology. Smart people and smart governance are fundamental for approaching the vision of smart city. It is very important to encouraging the citizen to become a more active and participative member of the community. It is necessary to meet new requirements from the labor market and people will be exposed to new changes which will be caused by vision of Industry 4.0 in future. These changes will be enormous and will require societal consensus and mainly support from the companies and government. This support could be given by social innovations. On this point the industrial companies should start more intensively cooperate with school and educational institutions and mainly participate in constitution of new studies programs. Well established industrial companies should take a part in special education and create opportunities for gaining professional experience from industrial practice.

It is very important for young people to give them chance to acquire outlook and practical experience during their studies at university, this could be realized by compulsory internships. Internships could be organized in two forms, by summer internship and school internship. Summer internship would be only voluntary should be a kind of extension of school internship. Internships should be realized in the range of three months with a very dynamic program that should be draft by special mentor for young students. For the best students there will be option to realize internship in an international environment in some divisions which operate worldwide. Individual candidates could perform tasks in field of manufacture, assembly, logistic, human resources, materials technology, and information systems and so on. By completing of internship these students could have preferential right to processing the bachelor, master or dissertation thesis. Students should during the internship gain a more realistic view on the work carried in industrial company. Students in this context could get practical insight into possible future career and afterwards they could motivate yourself to achieving better school results and identify yourself with future perspective job.

Another potential social innovation is applying the principles of age management in industrial practice within the European area, because age management solves problems of aging population, pressures of industrialization and current migration policy. Age management principles can be applied as social innovation, for example is it transfer of knowledge and skills of employees, then using knowledge capital of older generations and creating a cooperative corporate culture. Transfer of knowledge could be realized by mentoring. 
Introduction of mentoring as a daily activity in industrial companies could have a lot of contribution. Mentoring opens the door to new experience, knowledge, information, skills and competence. Mentoring among other things helps to more quickly adapt to the new environment as well as on colleagues. Mentoring allows to reach more qualified job performance, reduces mental effort, eliminate potential concerns. Mentoring in that way represents the great social innovation for everyday use in industrial companies. Mentoring could be used for adaptation of the newly accepted employees, for talent development, development of supervisor's persons in specific departments. Mentoring could be also used for sharing the internal knowledge and know-how.

Social innovations should encourage the development of society and simultaneously count with future changes, for that reason is important to find factors and relationships which facilitate the implementation of social innovation into the society and industrial companies.

Related to abovementioned there is a possibility to create a chance for the draw the financial support from the European Social Fund, which can be used to support the development of social innovation within the concept of smart city. The main objective is to increase the quality of education, acquired skills, training and development of society in all its aspects.

The main aim of the paper was to point out that any future changes will become an opportunity for social innovations to solve potential problems with qualification, flexibility or knowledge which will be required from human capital. Contribution of the paper consist in analysis and summarization of social impacts which will bring future on human capital.

\section{References}

1. THE TIMES OF INDIA. What is a 'smart city' and how it will work. [online]. Accessible at: http://timesofindia.indiatimes.com/What-is-a-smart-city-and-how-it-willwork/listshow/47128930.cms

2. Charbel Aoun. The Smart City Cornerstone: Urban Efficiency. [online]. Accessible at: http://www.digital21.gov.hk/relatedDoc/download/2013/079\%Electric\%20\%28Annex\%29.pdf 3. Elets. Lucknow ties up with EU on smart cities [online]. Accessible at: http://smartcity.eletsonline.com/lucknow-ties-up-with-eu-on-smart-cities/

4. Centre for cities. Smart Cities. [online]. Accessible at: http://www.centreforcities.org/wpcontent/uploads/2014/08/14-05-29-Smart-Cities-briefing.pdf

5. Hawaii International Conference on System Sciences. Understanding Smart Cities: An $\begin{array}{llll}\text { Integratove framework. } & \text { [online]. }\end{array}$ at:https://www.ctg.albany.edu/publications/journals/hicss_2012_smartcities/hicss_2012.pdf

6. Elets. Centre to guide cities for improving smart city plans. [online]. Accessible at: http://smartcity.eletsonline.com/centre-to-guide-cities-for-improving-smart-city-plans/

7. RACOUNTER. Connectivity in smart cities. [online]. Accessible at: http://raconteur.net/infographics/connectivity-in-smart-cities

8. LUBELCOVÁ, G. et al. 2011. Inovácie v sociálnych a verejných politikách: problémy konceptualizácie a nových nástrojov. Bratislava: UK. ISBN 978-80-223-3043-5

9. MULGAN, G. et al. 2007. Social Innovation: what i tis, why it matters and how it can be accelerated. Oxford, Said Business School.

10. CAGÁŇOVÁ, D. et al. 2015. Innovation in Industrial Enterprises and Intercultural Management. Zielona Góra: University of Zielona Góra. ISBN 978-83-933843-4-1. 